\title{
ANALISIS KEPUASAN PENGGUNA SISTEM INFORMASI AKADEMIK DI UIN SUNAN AMPEL SURABAYA MENGGUNAKAN END USER COMPUTING SATISFACTION
}

\section{Intan Novi Astutik, Yusuf Amrozi, Faris Muslihul Amin}

Universitas Islam Negeri (UIN) Sunan Ampel Surabaya, Indonesia

Email: intannovi813@gmail.com,yusuf.amrozi@uinsby.ac.id, faris@uinsby.ac.id

\begin{tabular}{ll}
\hline INFO ARTIKEL & ABSTRAK \\
\hline Diterima & Sistem Informasi Akademik (SIAKAD) merupakan sistem yang \\
25 Oktober 2021 & digunakan untuk membantu aktivitas belajar mengajar pada \\
Direvisi & suatu universitas. Sejak pertama kali dikembangkan, SIAKAD \\
05 November 2021 & Universitas Islam Negeri Sunan Ampel Surabaya (UINSA) \\
Disetujui & belum banyak dilakukan penelitian mengenai kepuasan \\
15 November 2021 & penggunanya sehinga diperlukan penelitian untuk mengetahui \\
\hline Kata Kunci: & efektivitas SIAKAD UINSA berdasarkan kepuasan \\
sistem informasi; & penggunanya. Penelitian ini bertujuan untuk mengetahui \\
SIAKAD; & kepuasan pengguna SIAKAD UINSA. Penelitian ini berjenis \\
kepuasan & kuantitatif dengan metode End User Computing Satisfaction \\
pengguna; & (EUCS). Sampel diperoleh dengan teknik random sampling \\
pengguna akhir; & sehingga didapatkan 392 responden yang terdiri dari mahasiswa, \\
EUCS & dosen, dan pegawai akademik bagian operator SIAKAD. Data \\
& yang diperoleh dianalisis dengan teknik analisis faktor. Hasil \\
& penelitian menunjukkan bahwa kepuasan pengguna berdasarkan \\
& indikator content sebesar 2,853; accuracy sebesar 0,708, format \\
& sebesar 0,616; ease of use sebesar 0,432; dan timeliness sebesar \\
& 0, 391. Berdasarkan hasil tersebut dapat diketahui bahwa \\
& indikator content memiliki pengaruh terhadap kepuasan \\
& pengguna SIAKAD di UINSA sedangkan keempat indikator
\end{tabular}

\section{ABSTRACT}

Academic Information System (AIS) is a system used to assist teaching and learning activities at a university. Since it was first developed, AIS Sunan Ampel Islamic State University Surabaya (UINSA) has not done much research on user satisfaction so research is needed to determine the effectiveness of AIS UINSA based on user satisfaction. This study aims to determine the satisfaction of users of AIS UINSA. This research is quantitative type with End User Computing Satisfaction (EUCS) method. The sample was obtained by random sampling technique so that 392 respondents were obtained consisting of students, lecturers, and academic employees of the SIAKAD operator section. The data obtained were analyzed using factor analysis techniques. The

How to cite:

E-ISSN:

Published by:
Astutik, I. N., Yusuf Amrozi, \& Faris Muslihul Amin. (2021) Analisis Kepuasan Pengguna Sistem Informasi Akademik Di UIN Sunan Ampel Surabaya Menggunakan End User Computing Satisfaction. Jurnal Syntax Admiration 2(11). https://doi.org/10.46799/jsa.v2i11.333 2722-5356 Ridwan Institute 


\section{Keywords:}

information

systems; SIAKAD;

user satisfaction;

end users; EUCS

results showed that user satisfaction based on content indicators was 2.853; accuracy was 0.708, format was 0.616; ease of use was 0.432; and timeliness was 0.391. Based on these results it can be seen that the content indicator has an influence on the satisfaction of SIAKAD users at UINSA while the other four indicators have not influenced user satisfaction.

\section{Pendahuluan}

Sistem informasi akademik merupakan kumpulan komponen-komponen, berupa fisik ataupun non-fisik dengan langkah-langkah yang saling berkesinambungan antara satu dengan yang lain sebagai satu kesatuan serta saling mempengaruhi dalam mengelola data akademik pada suatu instansi pendidikan menjadi suatu informasi yang bermanfaat untuk penggunanya (Mutia, 2014). Pada saat ini, teknologi sistem informasi mengalami perkembangan yang sangat pesat. Hal tersebut menyebabkan banyak organisasi ataupun instansi yang menggunakan teknologi informasi untuk mendukung segala aktivitas mereka sehingga dibutuhkan suatu sistem yang efektif dan efisien dalam memberikan informasi. Pemanfaatan teknologi yang baik harus sesuai dengan proses dan strategi bisnis suatu instansi ataupun organisasi untuk meningkatkan kinerja serta dapat meningkatkan nilai tambah dalam persaingan bisnis (Adityawarman, 2012). Penggunaan teknologi informasi sangat menetukan dalam siklus kehidupan suatu organisasi (Subiyakto et al., 2017) sehingga diperlukan penilaian atau evaluasi unjuk kerja suatu sistem yang telah dilaksanakan guna mengetahui seberapa suskses sistem tersebut dalam mencapai sasaran dan tujuan awal yang sudah ditetapkan (Prasti et al., 2018).

UIN Sunan Ampel Surabaya merupakan salah satu perguruan tinggi islam negeri di Indonesia yang mempunyai Sistem Informasi Akademik (SIAKAD) yang dikembangkan oleh Pusat Teknologi Informasi dan Pangkalan Data (PUSTIPD). SIAKAD UIN Sunan Ampel Surabaya merupakan suatu sistem informasi yang digunakan untuk menangani segala aktivitas perkuliahan seperti penjadwalan perkuliahan, penginputan nilai, pengisian kartu rencana studi, pembayaran UKT, dan segala aktivitas yang berkaitan dengan proses kelancaran perkuliahan. SIAKAD dapat diakses melalui Personal Computer $(P C)$ ataupun Mobile, namun penggunaan SIAKAD seringkali error pada saat pengisian kartu rencana studi yang telah terjadwal (Meha, 2019).

Hal tersebut menjadikan lembaga berkesan kurang mampu memfasilitasi mahasiswa dalam hal pelayanan perencanaan akademik. Asumsi tersebut dapat dilihat melalui kinerja suatu sistem di mana kinerja tersebut dapat diukur dengan meninjau tingkat kepuasan pengguna akhir (end user). Sedangkan tingkat kepuasan pengguna atas sistem yang digunakan yang menggambarkan bahwa tingkat kepuasan pengguna dapat diukur dari penilaian pengguna atas sistem yang dipergunakan (Arthur et al., 2008). Kepuasan pengguna diartikan seberapa baik sistem dalam mempengaruhi atau melampaui harapan pengguna (Kristiawan et al., 2016). Kepuasan pengguna merupakan salah satu model penelitian tidak langsung guna mengetahui efektivitas suatu sistem 
(Itmamudin, 2016). Salah satu model penilaian tidak langsung yaitu penilaian kepuasan sistem informasi pada end user dengan EUCS (Davis, 1989).

EUCS adalah penilaian terhadap suatu sistem informasi terkait dengan apa yang dirasakan pengguna ketika menggunakan sistem informasi (Suzanto \& Sidharta, 2015). Model EUCS mempunyai beberapa karakteristik yang terdiri dari isi (content), akurasi (accuracy), bentuk (format), kemudahan (ease of use) dan ketepatan waktu (timeliness) (Purwanto, 2016). Karakteristik tersebut yang membedakan antara EUCS dengan model lainnya di mana model lainnya, seperti Theory of Reased Action (TRA) yang menekankan pada faktor sikap yang didasarkan pada sudut pandang psikologi pengguna, model Technology Acceptance (TAM) yang menekankan pada penerimaan seseorang pada suatu sistem teknologi ditentukan pada konstruk kesan pengunaan atau perceived usefulness dan kesan kemudahan dalam kegunaan atau perceived ease of purpose, dan model Theory of Planned Behavior (TPB) yang menekankan pada persepsi kontrol perilaku atau perceived behavioral control dalam persepsi seseorang untuk mengukur tingkat kesulitan atau kemudahan dalam suatu perilaku atau tindakan (Aini et al., 2021). Hal tersebut menjadikan EUCS lebih unggul dalam hal menilai kepuasan pengguna menurut pengalaman yang telah pengguna alami.

Berdasarkan ulasan di atas dapat diidentifikasi bahwa penggunaan SIAKAD yang seringkali bermasalah pada saat pengisian KRS menimbulkan kesan bahwa lembaga belum mampu memfasilitasi mahasiswa dalam hal pelayanan perencanaan akademik. Oleh sebab itu, dibutuhkan suatu penelitian dengan tujuan untuk mengetahui kepuasan pengguna sistem dengan EUCS sebagai model acuan tinjuan. Hasil dari penelitian ini diharapkan dapat menjadi bahan pertimbangan bagi para pengambil kebijakan terkait, terutama bagi pihak-pihak pengelola SIAKAD yaitu PUSTIPD dalam mengembangkan sistem informasi akademik selanjutnya.

\section{Metode Penelitian}

Penelitian ini merupakan penelitian kuantitatif dengan menggunakan survei sebagai metode penelitian. Survey yaitu pengumpulan data pada penelitian dengan mengambil sampel dari suatu populasi menggunakan instrumen penelitian kuesioner (Singarimbun et al., 2011).

Alur penelitian ini digunakan untuk menggambarkan semua proses yang diperlukan dalam perancangan dan pelaksanaan penelitian. Alur penelitian dapat dilihat pada gambar 1 . 


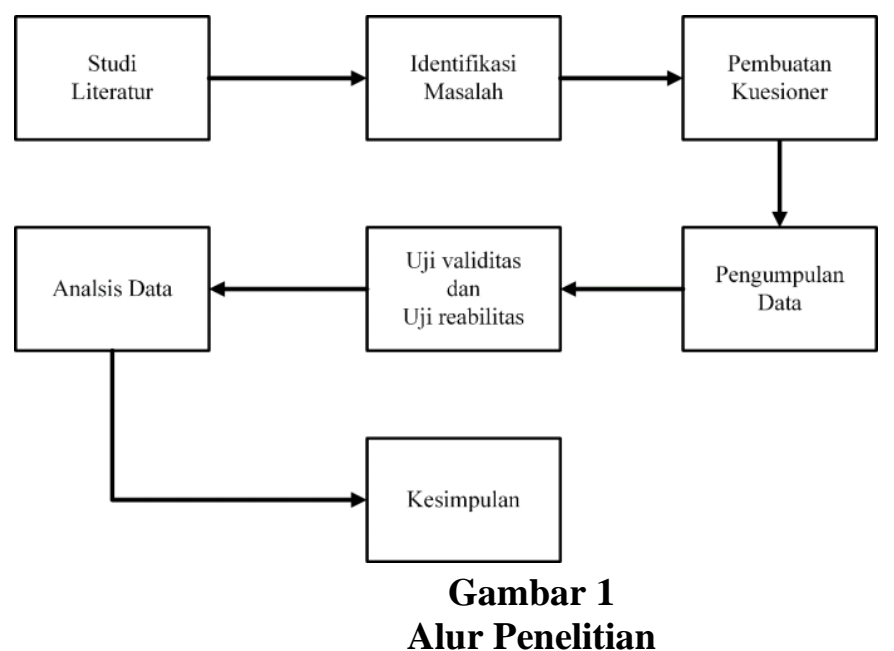

Gambar 1 Alur penelitian, tahap yang pertama yaitu studi literatur yang mana pada tahap ini digunakan untuk referensi terhadap teori yang berhubungan dengan penelitian serta untuk memperkuat permasalahan pada penelitian. Penelitian ini dilakukan untuk mengetahui kepuasan pengguna pada SIAKAD UIN Sunan Ampel Surabaya. Kemudian pembuatan kuesioner diadopsi berdasarkan model EUCS yang disebarkan kepada responden. Pembuatan instrumen penelitian ini mengacu pada 5 indikator pada EUCS yakni Content, Accuracy, Ease of Use, Format dan Timeliness. Setiap indikator pada EUCS memiliki pertanyaan yang memuat kepuasan pengguna ketika menggunakan suatu sistem. Pertanyaan yang digunakan menjadi instrumen kuesioner mengadopsi dari Doll dan Torkzadeh (Gelderman, 1998). Pengumpulan data dilakukan dengan menyebarkan kuesioner pada pengguna SIAKAD yaitu mahasiswa, dosen, dan pegawai akademik. Penentuan sampel menggunakan rumus slovin.

$$
n=\frac{N}{1+N(e)^{\wedge} 2}
$$

Dimana n yaitu jumlah sempel, $\mathrm{N}$ yaitu jumlah total populasi, dan e yaitu batas toleransi error. Pada penelitian ini jumlah total popuasi 19.975, dengan batas toleransi error 5\%. Sehingga didapatkan sampel 392 responden. Untuk mengetaui jumlah pada setiap strata pada populasi maka dihitung menggunakan proposionate stratified random sampling.

$$
n_{h}=\frac{n}{N} x N_{h}
$$

Yang mana $n_{h}$ merupakan sampel strata, n yaitu sampel, $\mathrm{N}$ yaitu populasi, dan $N_{h}$ adalah strata. Dari hasil perhitungan tersebut selanjutnya digunakan untuk menentukan sampel dengan menambahkan strata yang tidak propsional menggunakan disproportionate stratified random sampling untuk memenuhi sampel sebesar 392 responden. 
Kemudian kuesioner disebar sehingga diperoleh data, dan dilanjutkan dengan uji validitas dan reliabilitas menggunakan aplikasi SPSS untuk memastikan data tersebut valid dan reliabel. Selanjutnya dilakukan analisis data menggunakan analisis faktor untuk mengetahui faktor-faktor yang mendukung kepuasan pengguna SIAKAD. Data pada analisis faktor digunakan untuk menginterpretasikan suatu indikator baru yang berupa indikator bentukan (Supranto, 2010).

\section{Hasil dan Pembahasan}

\section{A. Hasil Penelitian}

EUCS merupakan salah satu model yang digunakan untuk mengevaluasi suatu sistem informasi dengan mengukur tingkat kepuasan pengguna sistem. Model EUCS memiliki lima indikator yang digunakan dalam mengukur kepuasan pengguna yaitu Content, Accuracy, Format, Ease of Use, dan Timeliness. Berikut ini daftar pertanyaan kuesioner dengan pengkoden X1 (Content), X2 (Accuracy), X3 (Format), X4 (Ease of Use), dan X5 (Timeliness) dapat dilihat pada Tabel 1.

\section{Tabel 1}

\begin{tabular}{ll}
\hline Indikator & \multicolumn{1}{c}{ Pertanyaan } \\
\hline $\mathbf{X 1 . 1}$ & Apakah sistem memberikan informasi yang Anda butuhkan? \\
\hline $\mathbf{X 1 . 2}$ & Apakah informasi dari konten memenuhi kebutuhan Anda? \\
\hline $\mathbf{X 1 . 3}$ & Apakah sistem memberikan laporan seperti yang Anda butuhkan? \\
\hline $\mathbf{X 1 . 4}$ & Apakah sistem memberikan informasi yang cukup? \\
\hline $\mathbf{X 1 . 5}$ & Apakah Anda menemukan output yang relevan? \\
\hline $\mathbf{X 2 . 1}$ & Apakah sistem memberikan data yang akurat? \\
\hline $\mathbf{X 2 . 2}$ & Apakah Anda puas dengan keakuratan sistem? \\
\hline $\mathbf{X 2 . 4}$ & Apakah Anda merasa output dari sistem dapat diandalkan? \\
\hline $\mathbf{X 3 . 1}$ & Apakah Anda merasa dapat mengandalkan sistem? \\
\hline $\mathbf{X 3 . 2}$ & Apakah output yang disajikan dapat digunakan? \\
\hline $\mathbf{X 3 . 3}$ & Apakah informasi yang disajikan jelas? \\
\hline $\mathbf{X 3 . 4}$ & Apakah Anda puas dengan tata letak output? \\
\hline $\mathbf{X 4 . 1}$ & Apakah output yang dihasilkan mudah dimengerti? \\
\hline $\mathbf{X}$ X.2 & Apakah sistem ini user friendly? \\
\hline $\mathbf{X}$ 3.3 & Apakah sistemnya mudah digunakan? \\
\hline $\mathbf{X 5 . 2}$ & Apakah sistem ini efisien? \\
\hline
\end{tabular}

Berdasarkan kuesioner tersebut diperoleh skor rata-rata tanggapan seperti yang ditunjukkan.

Tabel 2

\begin{tabular}{lcccc}
\hline Indikator & $\boldsymbol{N}$ & Mean & & Std. Deviation \\
\hline & Statistic & Statistic & Std. Error & Statistic \\
\hline Content X1 & 392 & 17.8138 & .12412 & 2.45752 \\
\hline Content X2 & 392 & 14.1403 & .09930 & 1.96600 \\
\hline Content X3 & 392 & 13.6709 & .12091 & 2.39381 \\
\hline Content X4 & 392 & 10.6454 & .08284 & 1.64006 \\
\hline Content X5 & 392 & 7.1250 & .05796 & 1.14753 \\
\hline
\end{tabular}


Berdasarkan analisis faktor untuk masing-masing indikator diperoleh hasil seperti yang ditunjukkan.

\section{Tabel 3}

\begin{tabular}{ll}
\hline Indikator & Hasil \\
\hline Content $(X 1)$ & 2.853 \\
\hline Accuracy $(X 2)$ & 0.708 \\
\hline Format $(X 3$ & 0.616 \\
\hline Ease of Use $(X 4)$ & 0.432 \\
\hline Timeliness $(X 5)$ & 0.391 \\
\hline
\end{tabular}

Berdasarkan hasil yang ditunjukkan tabel 3 dapat diketahui bahwa hanya indikator Content (X1) yang memiliki nilai lebih besar dari $1(>1)$ yang berarti X1 merupakan satu-satunya faktor yang mempengaruhi kepuasan pengguna SIAKAD di UINSA. Sedangkan indikator Accuracy (X2), Format (X3), Ease of Use (X4), dan Timeliness (X5) mendapatkan nilai lebih kecil dari $1(<1)$ yang berarti keempat indikator tersebut belum mempengaruhi kepuasan pengguna (hasil tersebut dapat diilustrasikan uga dalam bentuk diagram scree plot seperti yang ditunjukkan Gambar 2.

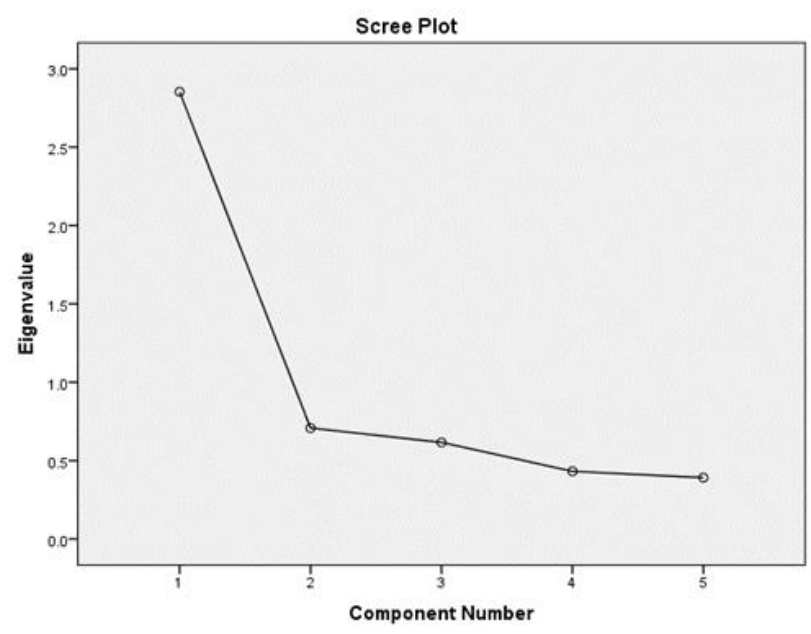

\section{B. Pembahasan}

Dalam menganalisis SIAKAD di UINSA penulis menggunakan model EUCS yang terdiri dari 5 indikator yaitu isi (content), akurasi (accuracy), bentuk (format), kemudahan (ease of use) dan ketepatan waktu (timeliness). Indikator dalam model EUCS dinyatakan mempengaruhi kepuasan pengguna apabila mempunyai nilai $>1$. Sehingga peneliti menggunakan model EUCS sebagai dasar menganalisis dan dari hasil penelitian ini diharapkan dapat membantu dalam pengembangan SIAKAD UINSA. Pada analisis didapatkan hasil bahwa pada (1) X1 adalah Indikator Contents, yakni nilai korelasi Indikator ini dengan faktor 1 adalah sebesar 0,758, (2) pada X2 adalah Indikator Accuracy, yakni nilai korelasi Indikator ini dengan faktor 1 adalah 
sebesar 0,814, (3) pada X3 adalah Indikator Format, yakni nilai korelasi Indikator ini dengan faktor 1 adalah sebesar 0,817, (4) pada X4 adalah Indikator Ease of Use, yakni nilai korelasi Indikator ini dengan faktor 1 adalah sebesar 0,666, dan (5) pada X5 adalah Indikator Timeliness, yakni nilai korelasi Indikator ini dengan faktor 1 adalah sebesar 0,711. Sehingga dari 5 indikator tingkat kepuasan pengguna, terdapat 4 indikator yang memiliki nilai component matrix $<1$.

\section{Kesimpulan}

Berdasarkan hasil penelitian yang diperoleh dapat disimpulkan bahwa faktor yang dapat mempengaruhi kepuasan pengguna Sistem Informasi Akademi (SIAKAD) di UIN Sunan Ampel Surabaya dengan menggunakan lima indikator pada EUCS yaitu indikator Content (X1) dengan nilai lebih dari 1 (> 1), sedangkan indicator Accuracy $(X 2)$, Format (X3), Ease of Use (X4), dan Timeliness (X5) tidak mampu mempengaruhi kepuasan pengguna karena mempunyai nilai kurang dari $1(<1)$. 
Analisis Kepuasan Pengguna Sistem Informasi Akademik di UIN Sunan Ampel

Surabaya Menggunakan End User Computing Satisfaction

\section{BIBLIOGRAFI}

Adityawarman, A. (2012). Pengukuran Tingkat Kematangan Penyelarasan Strategi Teknologi Informasi Terhadap Strategi Bisnis Analisis Menggunakan Framework Cobit 4.1 (Studi Kasus PT. Bri, Tbk). Jurnal Akuntansi Dan Auditing, 8 (2), 166177. Google Scholar

Aini, N., Ridwandono, D., \& Safitri, E. M. (2021). Analisis Kepuasan Pengguna Sistem Informasi Akademik Di Universitas Bhayangkara Surabaya. Jurnal Informatika Dan Sistem Informasi (JIFoSI), 2 (1), 26-33. Google Scholar

Arthur, A., Andry, E., \& Abdurachman, E. (2008). Analisis Tingkat Kepuasan Pengguna Sistem Informasi Underwriting Pada PT. Tugu Pratama Indonesia. Jurnal Piranti Warta, 11 (01), 28-44. Google Scholar

Davis, F. D. (1989). Perceived Usefulness, Perceived Ease of Use, and User Acceptance of Information Technology. MIS Quarterly: Management Information Systems, 13 No. 3, 319-340. Google Scholar

Gelderman, M. (1998). Translation and validation of the Doll and Torkzadeh end user computing satisfaction instrument. Proceedings of the Hawaii International Conference on System Sciences, 6 (c), 537-545.

https://doi.org/10.1109/hicss.1998.654814. Google Scholar

Itmamudin, I. (2016). Analisis Kepuasan Pengguna Opac dan Dampaknya Terhadap Loyalitas Di Perpustakaan Stain Salatiga. Libraria: Jurnal Perpustakaan, 2 (2), 1 19. Google Scholar

Kristiawan, D., Sunarto, \& Sabandi, M. (2016). Kualitas Sistem, Kualitas Informasi, Kualitas Pelayanan, Kepuasan, Manfaat Dalam Pembelajaran. Jurnal Ilmiah, hal 1. Google Scholar

Meha, R. H. (2019). Analisis kepuasan pengguna sistem informasi akademik di UIN Syarif Hidayatullah Jakarta. Fakultas Sains dan Teknologi UIN Syarif Hidayatullah Jakarta. Google Scholar

Mutia, I. (2014). Perancangan Sistem Informasi Akademik Dengan Teknologi Short Message Service (SMS) Pada XYZ. Faktor Exacta, 7 (3), 211-223. Google Scholar

Prasti, .D, Winarno, .W .W, \& Henderi. (2018). Analisis Kinerja Sistem Informasi Manajemen Universitas Cokroaminoto Palopo. Google Scholar

Purwanto. (2016). Analisis Penerimaan dan Kepuasan Pengguna Sistem Informasi Akademik Menggunakan Struktural Equation Modelling. Google Scholar

Singarimbun, Masri, Effendi, \& Sofian. (2011). Metode Penelitian Survay. PT. Pustaka LP3ES Indonesia. Google Scholar 
Intan Novi Astutik, Yusuf Amrozi, Faris Muslihul Amin

Subiyakto, A., Ahlan, A. R., Kartiwi, M., \& Putra, S. J. (2017). Model Keberhasilan Proyek Sistem Informasi: Penjelasan Ringkas Pencatatan Hak Cipta No. 01835, In Cyber and IT Service Management (CITSM), 2017 5th International Conference on, 1-12. Google Scholar

Supranto, J. (2010). Statistik Teori dan Aplikasi. UI Press. Google Scholar

Suzanto, B., \& Sidharta, I. (2015). Pengukuran End-User Computing Satisfaction Atas Penggunaan Sistem Informasi Akademik. Jurnal Ekonomi, Bisnis \& Entrepreneurship, 9 (1), 16-28. Google Scholar

\section{Copyright holder:}

Intan Novi Astutik, Yusuf Amrozi, Faris Muslihul Amin (2021)

First publication right:

Jurnal Syntax Admiration

This article is licensed under:

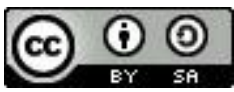

